\title{
Lazy or Greedy? Impact of Xenophobic Beliefs on Natives' Attitudes towards Redistribution
}

\author{
Raul Magni Berton \\ University of Grenoble, Science po Grenoble, PACTE, Grenoble, France \\ Email: raul.magniberton@iepg.fr
}

Received October $22^{\text {nd }}, 2012$; revised November $26^{\text {th }}, 2012$; accepted December $13^{\text {th }}, 2012$

\begin{abstract}
Several recent accounts have shown that anti-immigrant feeling among citizens seems to reduce the support for the welfare state. As a consequence, the rise of immigration could produce a deep change in industrialized countries' social security systems. This paper provides evidence that support for redistribution is not decreased by generic xenophobia, but by a specific kind of xenophobic belief. It also shows that some other xenophobic beliefs tend rather to produce a demand for governmental protection programs. Based on a multivariate analysis on individual and contextual French data, findings show that the support for social protection programs is positively related to the fear of competition from immigrants and negatively with the fear that immigrants strain the welfare state. This result can be generalized to other countries where "redistributive xenophobia" is much more widespread.
\end{abstract}

Keywords: Immigration; Xenophobia; Welfare State; France; Redistribution

\section{Introduction}

The issues linked to immigration have been multiplying in western democracies. During the last decade, security, intolerance, national identity, unemployment or the welfare state, have all been associated with the rise in immigration. Particularly, several studies have provided evidence of a negative correlation between income redistribution and the rise in immigration (Finseraas, 2008; Roemer, Lee, \& Van Der Straeten, 2007; Senik et al., 2009; Eger, 2010). The general explanation for this relationship is that the welfare state implies a certain concept of community: the shared burdens and benefits of the welfare state are acceptable so long as everyone shares the same features (McGhee \& Neiman, 2010). So, citizens tend to show less solidarity with "different" people and wish to decrease the generosity of state benefits. Assuming that diversity depends on linguistic, ethnic or racial features, some studies suggest that fractionalization reduces the size of the welfare state (Mueller \& Murrel, 1986; James, 1993; Alesina \& La Ferrara, 2005). This fact leads Alesina and Glaeser (2004: p. 11) to predict that "if Europe becomes more heterogeneous due to immigration, ethnic divisions will be used to challenge the generous welfare state".

However, other recent studies have shown that such a causal link is not so robust, and other factors have to be considered (Crepaz, 2008; Johnston et al., 2010). Particularly, reducing solidarity does not automatically imply a decrease in support for social protection.

Among the arguments put forward, Alesina and Glaser (2004) noted that if the "different" minority is on average richer than other people, probably redistributive policies will be massively supported. This positive relationship between minorities and redistribution was observed in the first half of the twentieth century, in Belgium. Before 1970, the Walloons were both richer and less numerous than the Flanders. This can explain the high level of redistribution in this country, contrary to what happens in other linguistically fragmented countries, such as Switzerland or Canada. So, the absence of feelings of solidarity towards immigrants can lead to increasing support for the Welfare State if redistribution allows the majority group to be favoured, or protected from minorities (Luttmer, 2001).

The aim of this paper is to clarify the link between beliefs about immigrants and preferences for redistribution. I will argue that there is no causality between general attitudes towards immigration and support for the welfare state, but some specific beliefs about immigrants cause specific attitudes towards social protection. Particularly, beliefs about immigrants can be redistribution-oriented or redistribution-neutral. They are redistribution-neutral if the belief does not lead individuals to have a particular opinion about redistribution. On another hand, the beliefs about immigrants are redistribution-oriented if they bring people to a particular opinion about redistribution. The redistribution-oriented beliefs are psychologically linked to a redistributive preference. Moreover, they may be positively or negatively oriented. According to the Alesina and Glaeser (2004) study, for example, believing that immigrants are rich is positively oriented to redistribution, whereas perceiving them as poor produces a negative opinion of redistribution.

The case studied in this article is France in 2008. France is one of the top three countries receiving the highest number of immigrants each year (with Germany and the UK), and its total taxation as a percentage of GDP is much higher than both other countries and among the highest in Europe according to the OECD Revenue Statistics in 2008. Politically, the traditional and the extreme right have paid considerable attention to this issue. In 2002 the extreme right-wing candidate for the presidential election came second. In 2004 a law was voted banning Muslim women from wearing veils - as an ostentatious religious sign - in public schools and other public buildings. In 2007 the Ministry of National Identity was set up. These events are the most salient examples to illustrate how important immigration and diversity issues are. Finally, previous studies have 
shown that immigration in France reduces voter preferences for expanding the size of the public sector (Roemer \& Van Der Straeten, 2005), even if public opinion remains strongly attached to the welfare state (Bréchon \& Tchernia, 2009).

It is possible to formulate the purpose of this article as a study of attitudes towards social protection focusing on the immigration issue. The aim is not to provide a complete model to explain preferences for redistribution, but to evaluate in which way immigration can influence these preferences. I will proceed in four steps. The first section develops the theoretical approach and the main testable hypotheses. The second section presents the empirical data and the estimation strategy used to test both hypotheses. The third section provides the main findings about the link between beliefs about immigrants and preferences for redistribution. Finally, the fourth section provides a discussion of these results.

\section{Theoretical Account}

\section{Redistribution-Oriented Beliefs}

The general assumption of this paper is that citizens - or a proportion of them - show less solidarity with immigrants than with one another (Habyarimana et al., 2007). I also consider that the proportion of people showing more solidarity with immigrants than with fellow citizens is negligible. Thus, even if most people are as concerned by immigrants as by fellow citizens, politically, the minority who is the least favourable towards immigrants can decisively influence governmental policies. This paper will focus the analysis on this minority.

As I pointed out above, beliefs about immigrants could influence the attitudes towards redistribution in two different ways. On the one hand, if people believe that immigrants are unemployed, they will infer that immigrants take advantage of the welfare system. If citizens don't wish to pay for immigrants, they will reduce their support for the welfare system. On the other hand, if people believe that immigrants are employedand perhaps disposed to work a great deal for a low incomethey would then tend to deduce that immigrants will take their jobs away. In this case, they will feel protected by the welfare system and will approve of it. Figure $\mathbf{1}$ graphically summarizes this double causal relationship.

Column A shows a psychological pattern leading people to demand more state responsibility in the citizens' welfare. The

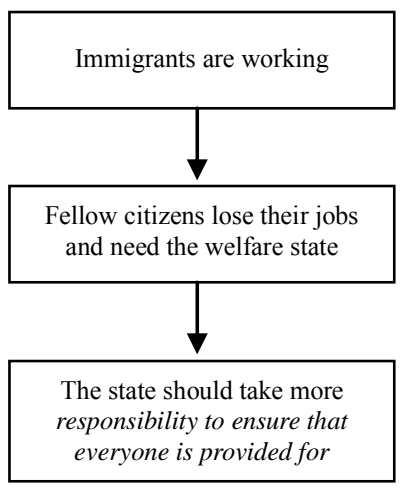

(a)

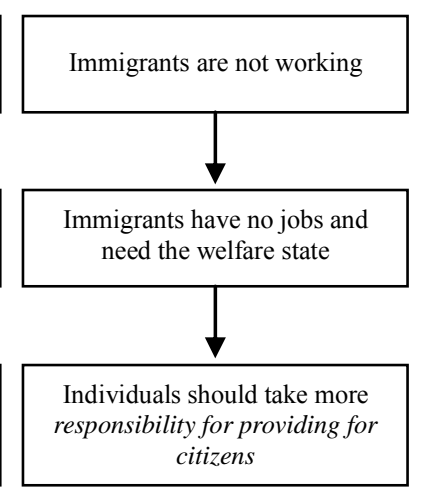

(b)
Figure 1.

Opposite causalities linking attitudes towards immigrants and preferences for redistribution. key beliefs - immigrants are hard working and therefore tend to take jobs away from local citizens - are called here redistributive xenophobia. The redistributive impact of immigration is a particular case of the broader effect of the risk of future income loss on preferences for redistribution (Cusack et al., 2006; Iversen \& Soskice, 2001; Moene \& Wallerstein, 2001). Some citizens might believe that immigrants pose a threat to current or future income and thus become more supportive of government responsibility.

Column B sets out the redistribution-averse psychological pattern: if immigrants are perceived as chronically unemployed - or simply poorer - this can lead to increased taxes for redistribution. As a result, some citizens may demand less state responsibility in the citizens' welfare. This mechanism leads to the expected negative correlation between support for the welfare state and the rise in immigration described above.

Finally, Figure 1 uses the government responsibility as a proxy for redistribution, social protection and the welfare state. Although these concepts are slightly different, they all suppose some state responsibility in citizens' living conditions. State (vs individual) responsibility for people's needs can imply some forms of unredistributive welfare as well as strictly redistributive measures. In this article, the concepts of welfare or redistribution refer to the general idea of state responsibility for citizens' welfare.

\section{Data and Methodology}

In order to test both causality patterns, I have used the latest wave of the European Values Survey conducted in 2008 in France, partly with a random sampling $(n=1501)$ and partly with a stratified sampling $(n=1570)$. Moreover, with respect to the available EVS data, some specific questions have been introduced (Bréchon \& Tchernia, 2009) ${ }^{1}$. Since this study only concerns the natives' attitudes, I eliminated people who do not have French nationality, reducing the sample to 2958 respondents.

In addiction to individual data, I used aggregate data provided by the INSEE (the French Institute for statistics and economic data). These contextual data relate to the smallest French administrative scale i.e. the county (département). Into our sample, the smallest county has about 200,000 inhabitants and the largest about 2,500,000, due to the presence of metropolis. Among the 96 metropolitan French counties, the French respondents of WVS live in 86 different counties. On average, a county represents 1.16 percent of the respondents (i.e. around 36 respondents). The least represented county makes up 0.26 percent of the survey and the most represented 5.21 percent. The distribution of the survey across the counties is related to the demographic weight of the counties in the true French population.

\section{Key Variables}

The key variables correspond to the second and the third steps of Figure 1. For the third step - the dependent variablethe question was formulated in identical terms in the question-

\footnotetext{
${ }^{1}$ The French sample of the European Values Survey data has been chosen for two reasons. First - contrary to the European Social Survey, for example-it allows the identification of the county scale in which respondents live. Second, it offers a large variety of questions on values, especially in questions linked to immigration.
} 


\section{R. MAGNI BERTON}

naire. Respondents have to place themselves on a ten point scale in which 1 corresponds to the statement "Individuals should take more responsibility for providing for citizens" and 10 corresponds to "The state should take more responsibility to ensure that everyone is provided for". Thus, the higher this indicator is, the more people support state responsibility for needs (see Table 1). In this first analysis, this indicator will be the dependent variable.

The second group of variables - referring to the second stepmeasures specific beliefs about immigration and is the main independent variable. For the first time in the European Values Surveys, five questions on the link between immigration and the welfare state were asked. These questions are also proposed with a ten point scale, and two of them test the model, asking whether immigrants take jobs away (10) or not (1) and whether immigrants are a strain on the welfare system (10) or not (1). It is important to note that the correlation between both variables is high $(\mathrm{r}=.55)$. This could indicate that, contrary to what I had assumed, many people answer both questions in a similar way. In fact, there is a set of people that are systematically opposed or systematically favourable to immigrants. So, they believe that whatever immigrants do, they are a threat, or a resource, for the society. For example, the most direct question is whether immigrants will become a threat to society or not. This question is highly correlated with the other more specific questions such as those about jobs $(r=.63)$ and those about the welfare state $(r=.74)$. Finally, correlating the questions about immigration (including those about crime and cultural life, described below), we can observe that the statistical relationship between the two independent variables considered here is the weakest. Assuming that people who are either positively or negatively disposed towards immigrants would answer both questions in the same way, it is interesting to understand why more than $2 / 3$ of the sample answered the two questions differently and what the consequences of this fact are at the aggregate level.

This differential answering has also been measured with a ternary variable in which respondents are coded 0 if they answer both questions in the same way. These respondents are not sensitive to any particular issue. When individuals are coded with 1 , they agree more with the idea that immigrants strain the welfare system than that they take jobs away (WS sensitive hereafter). This group is expected to be redistribution-averse and it corresponds to column B in Figure 1. Finally, people coded with 2 are more afraid of losing jobs due to immigration. They are Job sensitive and they should support social protection. This measure does not consider the level of fear of immigrants,

Table 1.

Description of the key variables.

\begin{tabular}{ccc}
\hline & Mean & Std. Err. \\
\hline State vs Individual responsibility & 6.334 & .045 \\
Strain the WF & 5.097 & .050 \\
Take jobs away & 3.799 & .051 \\
& $\mathrm{~N}$ & $\%$ \\
Job sensitive & 474 & 15.43 \\
No sensitive & 907 & 29.53 \\
WS sensitive & 1690 & 55.03 \\
\hline
\end{tabular}

because people answering 10 for both questions have the same score as the individuals answering 1 for both questions. Moreover, a respondent who puts 7 for welfare strain and 8 for jobs is definitely classified as job sensitive - as are respondents putting 0 on welfare strain and 10 on jobs. Therefore, this indicator captures the preference, but not the intensity of this preference. Basically, it supposes that perceiving any difference between both issues is fundamentally different from perceiving a higher or a lower difference. This indicator is adapted to measure why people are more sensitive to one issue than another, beyond their degree of xenophobia or their particular sensitivity to one issue. Table 1 describes these main variables.

Moreover, the respondents had the possibility to give their opinion on two other specific questions about the way in which immigration could threaten them. Both questions were formulated on a ten point scale. Respondents could say if immigrants undermine cultural life in France $(10=$ totally agree), called Sap culture. They could also agree with the idea that immigrants increase crime $(10=$ totally agree). These two measurements of xenophobia are expected to be redistribution-neutral, i.e. they should not have any psychological impact on preferences for redistribution.

Finally, I have also taken into account a broader negative attitude towards immigrants that is not related to a specific belief. Respondents can strongly agree (1) or strongly disagree (5) with the statement: "Today in France, there are too many immigrants". This variable - called Tolerance - measures a simple attitude concerning the number of immigrants living in France, but it doesn't specify the reasons for which there are too many immigrants or not.

\section{Control Variables}

Above all, I have to test that beliefs about immigration is a cause, and not an effect, of attitudes towards state protection. In order to identify the specific impact of beliefs about immigration on state protection, the general ideological predisposition towards free market politics is controlled. Negative attitudes towards the free market (hereafter Oppose Free Market) are measured from four questions. The first question concerns competition. Respondents placed themselves on a ten-point scale in which 1 meant "competition is good. It stimulates people to work hard and develop new ideas" and 10 was "Competition is harmful, it brings out the worst in people". The second question is about private property. In the ten-point scale, 1 corresponds to the opinion: "private ownership of business and industry should be increased" and 10 to the opinion "government ownership of business and industry should be increased". The last two questions are specific to the French questionnaire. The first concerns entrepreneurship. People can agree (1) or not (4) with the sentence: "entrepreneurship should be increased". The second, based on the same structure, deals with profit. The sentence is "a working economy needs private companies to generate profits". The addition of these opinions about competition, private property, entrepreneurship and profit forms the Oppose Free Market variable. If beliefs about immigration were an effect of the attitudes towards the market, their effect should be captured by this control variable.

I have also controlled for income (annual household income on 14 categories centred on the median income level), expecting that the richer people are, the less willing they are to pay taxes, and, inversely, when people are poor, they ask for more 


\section{R. MAGNI BERTON}

redistribution. Both variables measure the impact of selfish beliefs, related to the personal economic situation of respondents.

I have taken into account three major demographic characteristics such as Gender ( 1 = female), Age and Education (in 5 points, adapted to the French system). The two former demographic variables are expected to have a positive influence: older people and females should be more likely to support redistribution (Blekesaune \& Quadagno, 2003; Keely \& Tan, 2008).

Finally, two cultural variables are considered: the religiousness of the respondent-associated traditionally with a lower level of support for welfare state, and the presence of parents born outside France (hereafter Immigrant Parents). This is the case for $17 \%$ of respondents, $9 \%$ of which have both parents born outside France. This variable could influence the relationship between attitudes towards social protection and beliefs about immigrants, because it can have an impact on both of them.

\section{Contextual Effects}

The relationship between the first and the second step of Figure 1 can be tested with contextual variables. According to this, people's beliefs should be influenced by the fact that immigrants are working or not. I assume here that people observe the reality around them. According to INSEE data, immigrants are about twice as likely to be unemployed as French citizens in 2008 (15\% vs 7\%). So, this fact could explain why people tend to perceive immigrants as straining the Welfare State instead of taking jobs away. Nevertheless, at the county scale, the ratio of the unemployment rate of immigrants to that of French citizens varies from 1.2 (almost the same) to 3.7. So immigrants are globally more unemployed than French citizens, but it is not perceived this way in each county. This unemployment ratio is the contextual variable used here: it corresponds to what natives perceive around them and it is not sensitive to the absolute level of unemployment. According to the general hypothesis, in counties with low-employment levels of migrants according to natives, people are expected to be afraid to pay for immigrants. Conversely, in counties with many working immigrants, people sense higher competition with immigrants in the labour market.

\section{Results}

\section{Estimation Strategy}

The objective of this section is to test the presumed causal relationship between beliefs about immigration, described in the second step in Figure 1, and the tendency to believe that the state should take more care of citizens, represented by the third step.

With regard to the dependent variable, Table 2 uses two different estimation strategies. In columns named Oprobit, the dependent variable is on a ten-point scale. Thus, for these variables, I have to carry out an ordered probit model with an estimation based on the maximum log-likelihood. The second strategy, in columns called Probit, is a probit analysis in which the dependent variable is a dummy. I have considered the responses from values 1 to 5 as 0 , and the values from 6 up to 10 , as 1 . In this case the value 1 means "The state should take more responsibility to ensure that everyone is provided for" and the value 0 indicates disagreement with this opinion.

Section 3.2 compares the effects of generic attitudes towards
Table 2.

Beliefs about immigrants and support for social protection.

\begin{tabular}{|c|c|c|c|c|c|}
\hline & Oprobit 1 & Oprobit 2 & Probit 1 & Probit 2 & Probit 3 \\
\hline \multicolumn{6}{|l|}{ Immigrants } \\
\hline Tolerance & $\begin{array}{l}.046{ }^{* *} \\
(.017)\end{array}$ & & $\begin{array}{l}. \mathbf{0 4 2} \\
(.022)\end{array}$ & & $\begin{array}{l}.034 \\
(.027)\end{array}$ \\
\hline Take jobs away & & $\begin{array}{l}.026^{* * *} \\
(.011)\end{array}$ & & $\begin{array}{l}.032^{* * *} \\
(.014)\end{array}$ & $\begin{array}{l}.034^{* *} \\
(.013)\end{array}$ \\
\hline Strain the WS & & $\begin{array}{c}-.024^{* *} \\
(.011)\end{array}$ & & $\begin{array}{c}-.034^{* *} \\
(.014)\end{array}$ & $\begin{array}{r}-.037^{* *} \\
(.013)\end{array}$ \\
\hline Sap culture & & $\begin{array}{l}-.008 \\
(.011)\end{array}$ & & $\begin{array}{l}-.002 \\
(.015)\end{array}$ & \\
\hline Increase crime & & $\begin{array}{l}-.003 \\
(.011)\end{array}$ & & $\begin{array}{l}-.016 \\
(.015)\end{array}$ & \\
\hline \multicolumn{6}{|l|}{ Other I.D. } \\
\hline Oppose F. market & $\begin{array}{l}.093^{* *} \\
(.008)\end{array}$ & $\begin{array}{l}. \mathbf{0 8 8} 8^{* *} \\
(.005)\end{array}$ & $\begin{array}{l}. \mathbf{0 8 8} \\
(.007)\end{array}$ & $\begin{array}{l}\mathbf{. 0 8 8}^{* *} \\
(.007)\end{array}$ & $\begin{array}{l}. \mathbf{0 8 8} \\
(.007)\end{array}$ \\
\hline Income & $\begin{array}{c}-.016 \\
(.007)\end{array}$ & $\begin{array}{c}-.015^{* *} \\
(.007)\end{array}$ & $\begin{array}{c}-.021^{* * *} \\
(.009)\end{array}$ & $\begin{array}{c}-.020^{* * *} \\
(.009)\end{array}$ & $\begin{array}{c}-.021^{* * *} \\
(.009)\end{array}$ \\
\hline Gender (female) & $\begin{array}{c}.054 \\
(.041)\end{array}$ & $\begin{array}{c}.051 \\
(.042)\end{array}$ & $\begin{array}{c}.051 \\
(.054)\end{array}$ & $\begin{array}{c}.048 \\
(.055)\end{array}$ & $\begin{array}{c}.052 \\
(.055)\end{array}$ \\
\hline Age & $\begin{array}{l}-.002^{*} \\
(.001)\end{array}$ & $\begin{array}{l}-.0017 \\
(.0012)\end{array}$ & $\begin{array}{l}-.0026 \\
(.0017)\end{array}$ & $\begin{array}{c}.002 \\
(.002)\end{array}$ & $\begin{array}{l}-.002 \\
(.002)\end{array}$ \\
\hline Education & $\begin{array}{c}-.053^{* *} \\
(.021)\end{array}$ & $\begin{array}{c}-.043^{* *} \\
(.021)\end{array}$ & $\begin{array}{c}-.074^{* *} \\
(.027)\end{array}$ & $\begin{array}{c}-.066^{* *} \\
(.027)\end{array}$ & $\begin{array}{c}-.071 \text { ** } \\
(.028)\end{array}$ \\
\hline Religiousness & $\begin{array}{l}-.005 \\
(.044)\end{array}$ & $\begin{array}{c}.013 \\
(.044)\end{array}$ & $\begin{array}{l}-.030 \\
(.057)\end{array}$ & $\begin{array}{l}-.013 \\
(.058)\end{array}$ & $\begin{array}{l}-.021 \\
(.058)\end{array}$ \\
\hline Migrants parents & $\begin{array}{c}.006 \\
(.034)\end{array}$ & $\begin{array}{l}.006 \\
(.035)\end{array}$ & $\begin{array}{c}.001 \\
(.045)\end{array}$ & $\begin{array}{l}-.003 \\
(.045)\end{array}$ & $\begin{array}{l}-.003 \\
(.045)\end{array}$ \\
\hline Constant & & & $\begin{array}{c}-1.44^{* *} \\
(.178)\end{array}$ & $\begin{array}{c}-1.24^{* *} \\
(.196)\end{array}$ & $\begin{array}{c}-1.40 \text { ** } \\
(.226)\end{array}$ \\
\hline Number of obs $=$ & 2531 & 2519 & 2531 & 2519 & 2516 \\
\hline $\operatorname{chi} 2=$ & $362^{* *}$ & $372^{* *}$ & $237^{* *}$ & $249^{* *}$ & $250^{* *}$ \\
\hline Pseudo R2 = & .03 & .03 & .07 & .08 & .08 \\
\hline
\end{tabular}

Note: ${ }^{* *} p<.05,{ }^{*} p<.1$.

immigration, on support for social protection, with those of specific beliefs. It shows that the analysis based on specific beliefs is more precise and offers quite different results. Section 3.3 focuses on the impact of unemployment ratio on the support for social protection and analyzes whether the sensitivity for specific immigration issues mediates such a relationship.

\section{Beliefs about Immigrants}

According to classic literature, negative attitudes towards immigration reduce support for the welfare state. Columns Oprobit 1 and Probit 1 confirm this prediction: global tolerance to immigrants positively influences support for social protection, independently to attitudes towards the free market. Also, the impact is less significant when the indicator of social protection is a dummy. Notice that education and income have a negative impact on support for social protection.

This estimation must be compared with those represented in columns Oprobit 2 and Probit 2, where the variable Tolerance 
is replaced with specific beliefs about immigrants. In these estimations, two specific beliefs have no significant impact on support for social protection (immigrants sap culture and increase crime), whereas two others have opposing signs. The belief that immigrants strain the welfare state decreases support for redistribution, whereas believing immigrants steal jobs increases this support.

So, the results concerning specific beliefs infirm the idea that negative attitudes towards immigration have a negative influence on support for social protection, since this influence depends on why people fear immigrants. Note that in the Probit 2 model, Take jobs away and Strain the WS coefficients are both more significant than that of Tolerance. Moreover, when these three variables are included in the same model (Probit 3), Tolerance loses its significance, while Take jobs away and Strain the WS don't. Finally, regarding Chi2 and the Pseudo R2, using specific beliefs slightly increases the relevance of the model.

It must be clarified here why Tolerance has a significant impact, whereas when analyzing specific beliefs such an impact is equivocal. The reason is that, as Table 1 shows above, there are in France many more people that think of immigrants as straining the welfare state instead of stealing jobs. This fact explains why - regarding attitudes - negative attitudes tend to make people oppose social protection, but when considering people's beliefs, results are less clear.

These results are robust and they hold with different estimations. The collinearity between the four beliefs about immigrants does not have an impact on results except in one important case: the variable "Take jobs away", taken without another "immigrant" variable, maintains its positive influence, but loses its significance at the .05 level. This variable's strongest and most significant impact appears when "Strain the WS" is controlled. To understand this result it is useful to consider the "attitude" effect. As I said above, 1/3 of the sample answered both questions in the same way. In France, people viewing immigrants as a threat tend to vote for the political parties not promoting redistributive policies and, inversely, people who are not afraid of immigration are more supportive of redistributive parties. Therefore, most people connect redistribution and tolerance for immigration in this ideological way (Roemer et al., 2007). When this effect is captured by another immigration variable such as Sap Culture or Increase Crime, it is possible to observe the real effect of the belief that immigrants take jobs away. This effect clearly encourages greater redistribution. In particular, comparing the respective coefficients, its impact is similar to that of the "Strain the WF" variable.

\section{Job and WS Sensitivity and Contextual Effects}

The previous section has shown that beliefs, rather than attitudes, matter. But to understand the process that brings about supporting social protection, Figure $\mathbf{1}$ has to be empirically operationalized. According to Figure 1, being more sensitive to the job issue is caused by the perception that immigrants are hard working and it produces greater support for social protection. On the other hand, sensitivity to the welfare state issue is due to a perception of immigrants as not working and leads to a decrease in support for social protection. Therefore, indirectly, the unemployment rate of immigrants can lead to greater or lesser support for social protection. The main hypothesis here is that the Unemployment Ratio that people perceive around them has an influence on the way in which they view the immi- grants $^{2}$.

In Table 3, the contextual variable Unemployment Ratio is added to the model and estimated with clustered standard errors $^{3}$. Moreover, I have dropped Religiousness and Migrant Parents, because they were insignificant in the previous model and they do not affect the results.

Columns Oprobit 1 and Probit 1 describe the indirect effect of the unemployment ratio on support for social protection. In both cases, its impact is - as expected - negative: the more unemployed immigrants there are, compared to natives, the less people support state responsibility. In the probit model, this effect is only significant at the $10 \%$ level. The other variables keep the impact observed above.

Let's now introduce the respondents' sensitivity. Compared to job sensitivity, WS sensitivity has a significant negative impact. In the probit model, no sensitivity coefficient is significantly different from job and WS sensitivity effects, whereas in the ordered model there is no significant difference between job sensitivity and no sensitivity.

More interesting, introducing these variables considerably weakens the impact of the contextual variable. The Unemployment Ratio has an impact on support for social protection, which is mediated by the kind of sensitivity. We can perceive this through the loss in significance and in the slope described by the coefficient of the Unemployment Ratio, when the variable related to the type of sensitivity is controlled ${ }^{4}$.

To sum up, the hypotheses summarized in Figure 1 are confirmed. When the immigrant unemployment rate is higher than that of natives, the native support for social protection decreases. The more unemployed immigrants there are the less generous natives are. But this effect becomes considerably weaker when people's sensitivities are controlled. In this case, when people perceive immigrants as straining the welfare state, they wish to reduce the welfare state. On the contrary, when natives perceive immigrants as job thieves, they increase their support for social protection. The insignificance of the contextual variable in this last case, confirms that its effect is captured by the sensitivity variables.

\section{Generalizing Results}

Overall, the welfare state does not always seem to suffer from fear of immigrants. Sometimes-when immigrants are perceived as job thieves, support for the welfare state increases. Inversely, when people worry about immigrants because they think they are lazy and take advantage of the welfare state, support for the welfare state decreases. Other kinds of xenophobic beliefs - immigrants sap our culture, or produce crime-are neutral, i.e. not significantly linked with support for redistribution. In France, immigration has a negative effect on public spending (Roemer \& Van Der Straeten 2005) probably because currently there are about three times more people who believe

\footnotetext{
${ }^{2}$ Of course, this is not a necessary consequence. Indeed, people can wrongly perceive immigrants as working or not working. In this article, only the impact of the real situation is tested.

${ }^{3}$ The error terms of the estimation could be correlated with unobserved features of the counties. It is possible that the errors are not identically and independently distributed. To solve this problem, we use a method to correct the variance of the errors known as "clustering correction". The corrected variance related to the counties provides corrected standard error of the estimated coefficients that do not suffer from heteroscedasticity.

${ }^{4}$ Note that when the sensitivity variables are controlled, the impact of the other variables is not affected, except for age. I cannot account for that.
} 
Table 3.

Sensitivity for immigration issues, unemployment ratio and support for social protection.

\begin{tabular}{|c|c|c|c|c|}
\hline & Oprobit 1 & Oprobit 2 & Probit 1 & Probit 2 \\
\hline \multicolumn{5}{|l|}{ Immigrants } \\
\hline \multicolumn{5}{|l|}{$\begin{array}{l}\text { Job sensitivity } \\
\text { (excluded) }\end{array}$} \\
\hline WS sensitivity & & $\begin{array}{l}-.166 * * \\
(.067)\end{array}$ & & $\begin{array}{l}-.303^{* *} \\
(.080)\end{array}$ \\
\hline No sensitivity & & $\begin{array}{l}-.082 \\
(.076)\end{array}$ & & $\begin{array}{c}-.019^{* *} \\
(.095)\end{array}$ \\
\hline \multicolumn{5}{|l|}{ Contextual } \\
\hline Unemployment ratio & $\begin{array}{l}-.078^{* *} \\
(.036)\end{array}$ & $\begin{array}{l}-.069^{*} \\
(.035)\end{array}$ & $\begin{array}{l}-.076^{*} \\
(.046)\end{array}$ & $\begin{array}{l}-.062 \\
(.045)\end{array}$ \\
\hline \multicolumn{5}{|l|}{ Other I.D. } \\
\hline Oppose F. market & $\begin{array}{l}\mathbf{. 0 8 9}^{* *} \\
(.006)\end{array}$ & $\begin{array}{l}. \mathbf{. 0 8 9}^{* * *} \\
(.006)\end{array}$ & $\begin{array}{l}. \mathbf{. 0 8 9}^{* * *} \\
(.007)\end{array}$ & $\begin{array}{l}. \mathbf{. 8 9 9}^{* * *} \\
(.007)\end{array}$ \\
\hline Income & $\begin{array}{l}-.011 \\
(.008)\end{array}$ & $\begin{array}{l}-.011 \\
(.008)\end{array}$ & $\begin{array}{l}-.016^{*} \\
(.010)\end{array}$ & $\begin{array}{r}-.017^{*} \\
(.010)\end{array}$ \\
\hline Gender (female) & $\begin{array}{l}.046 \\
(.043)\end{array}$ & $\begin{array}{l}.045 \\
(.043)\end{array}$ & $\begin{array}{l}.044 \\
(.053)\end{array}$ & $\begin{array}{l}.041 \\
(.053)\end{array}$ \\
\hline Age & $\begin{array}{c}-.002 \\
(.001)\end{array}$ & $\begin{array}{l}-.002 \\
(.0012)\end{array}$ & $\begin{array}{c}-.003^{*} \\
(.002)\end{array}$ & $\begin{array}{c}.002 \\
(.002)\end{array}$ \\
\hline Education & $\begin{array}{l}-.040^{*} \\
(.022)\end{array}$ & $\begin{array}{l}-.0^{*} 6^{*} \\
(.022)\end{array}$ & $\begin{array}{l}-.062^{* *} \\
(.027)\end{array}$ & $\begin{array}{l}-. .055^{*} \\
(.028)\end{array}$ \\
\hline Constant & & & $\begin{array}{l}-\mathbf{1 . 2 2} 2^{* *} \\
(.204)\end{array}$ & $\begin{array}{l}\mathbf{- 1 . 0 7 ^ { * * }} \\
(.202)\end{array}$ \\
\hline Number of obs $=$ & 2600 & 2581 & 2600 & 2581 \\
\hline chi $2=$ & $233^{* *}$ & $245^{* *}$ & $212^{* *}$ & $271^{* *}$ \\
\hline Pseudo R2 = & .03 & .03 & .07 & .08 \\
\hline
\end{tabular}

Note: ${ }^{* *} p<.05,{ }^{*} p<.1$.

that immigrants are lazy than people who believe they steal jobs (1690 vs 474 in the survey). But this fact is contingent. An inversion of these beliefs could lead to the inverse effect on support for public spending. As the results show, negative opinions of immigrants can have an effect on support for the welfare state, but this effect depends on the content of these negative opinions.

Results have also shown that this kind of redistributive xenophobia is rare in France. But in other parts of the world, the redistributive xenophobia is more developed. Figure 2 illustrates this hypothesis. The World Values Survey of 1999 on 54 countries around the world shows a strong negative correlation between believing that individuals (instead of the state) should take more responsibility for providing for themselves (shown by the mean of answers on the ten point scale described above) and believing that when jobs are scarce, employers should give priority to fellow citizens over immigrants (shown in percentage). Figure 2 illustrates at the aggregate level the evidence provided in France at the individual level. The fear of "working immigrants" increases support for redistribution.

Note that the recent accounts on the relationship between immigration and redistribution have underlined a negative cau- sality, confirmed by several empirical tests (Roemer et al., 2007; Soroka et al., 2006). But such tests focused on countries depicted at the bottom-right of Figure 2, especially the US, New Zealand, Australia and some North European countries. In these countries, few people have a redistributive xenophobia. Generalizing the findings of this paper, xenophobia decreases preferences for redistribution in countries where the redistributionaverse xenophobia has the upper hand. These countries are on the right of Figure 2. Inversely, xenophobia should increase preferences for redistribution in more redistributive xenophobic countries, depicted on the left of Figure 2.

According to the third wave of the World Values Survey, France is one of the top ten countries asking for less government intervention (support for government intervention is lowest in Sweden) and one of the six bottom countries to believe that fellow citizens should be employed as a priority. As I have also shown, the French are much more afraid that immigrants strain the welfare state than that they take jobs away. All these data tend to confirm that beliefs about immigrants, in France, are set in a way that predicts a drop in preference for redistribution. Of course, redistributive xenophobia also occurs, but considerably less. Similar cases include the US, the UK and several other western democracies.

\section{Conclusion}

The findings have shown two main points: firstly, the causal link between xenophobia and support for redistribution exists, but it depends on specific beliefs about immigrants. Second, these beliefs are partially explained by the effective integration of immigrants in the labor market. This section analyses the repercussions of these results on the current situation and on the literature on attitudes towards immigration.

Let us start with the complex causality linking xenophobia and support for state responsibility. Some accounts have stated that a homogeneous community produces strong feelings of solidarity. Immigration tends to break communities up, thus weakening solidarity (Habyarimana et al., 2007). This process would decrease support for redistribution. But, this argument is challenged by evidence provided here. Feelings of solidarity towards fellow-citizens can be reinforced if those people are threatened. So, immigration does not necessarily break communities up, but it can actually reinforce intra-community solidarity (Campbell, 2006). The "rally around the flag" (Mueller, 1973 ) is generally encouraged by politicians to face a foreign menace, which may be identified as a foreign country, but also as immigrants. The fear of losing jobs because of immigrants can be viewed as a foreign threat producing a preference for redistributing wealth and being protected by government.

As I have also shown, citizens afraid of "lazy immigrants" tend to decrease their support for redistribution. This result can also be understood as an effect of intra-group solidarity: people refuse to let their fellow-citizens pay for immigrants.

Other kinds of xenophobia have no significant impact on redistribution. So, the causal link between redistribution and attitudes towards immigration is contingent and depends on specific beliefs about immigrants. The causal relationship exists, but only in certain cases. Moreover, when it exists, it can go in two opposite directions: it can be positive or negative. It is also possible to reformulate this result, asserting that beliefs about immigrants have a causal relationship with preferences for redistribution, but this is not the case for attitudes towards immi- 


\section{R. MAGNI BERTON}

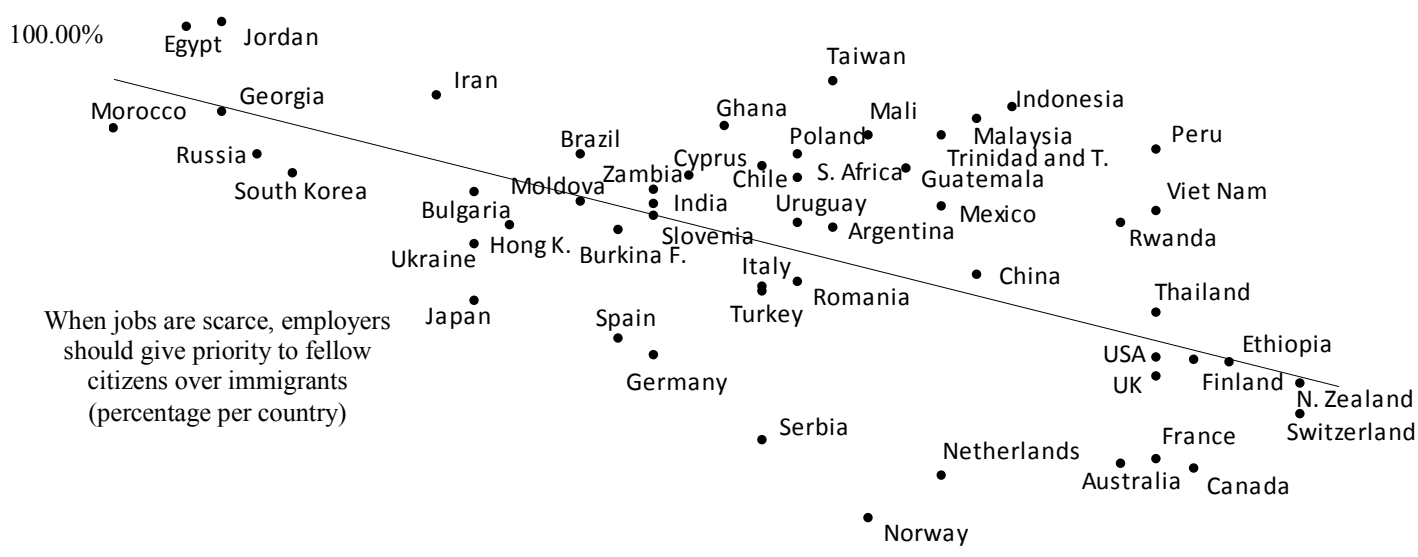

Individuals (vs. the state) should take more responsibility for providing for citizens (mean per country)

Sweden

$0.00 \%$

4

5

6

Figure 2.

Relationship between redistribution-seeking xenophobia (Y) and preference against state intervention (X) in 54 countries.

gration. So, to understand how xenophobia affects redistribution, it is necessary to explore on which beliefs xenophobia is based.

These beliefs are presumably affected by the real situation. When immigrants are working, natives fear for their jobs, whereas when immigrants are unemployed, natives are afraid of public spending. According to this point, politicians can indirectly exploit citizens' fears. Anti-redistributive governments have an incentive to manage a migratory policy leading to a high immigrant unemployment rate, in order to make people perceive immigrants as a strain for the welfare state and reject redistribution $^{5}$. On the other hand, pro-redistributive parties would do better to select immigrants and give them good opportunities to work in order to make the local citizens afraid of losing their jobs and give them a desire to be protected by the welfare state. This prediction seems quite correct, at least concerning the link between immigration and redistribution: in most countries, the same political parties defend both immigrants and redistribution.

Finally, the findings discussed above about the immigration issue have to be compared with findings provided by the literature on "racial fractionalization". Both questions - immigration and racial homogeneity - are empirically linked, but conceptually different. In Europe, immigrants are on average racially different from natives. But, in the US, especially in the twentieth century, there was maybe more racial fractionalization among natives than between natives and immigrants. In France, even if immigration is still associated with ethnic diversity, the percentage of Blacks or Arabs among natives is increasing. Today, a study on immigration in France can be considered as tallying with the racial diversity issue. In the future, we could compare the specific immigration effect and the racial diversity effect in most European countries.

${ }^{5}$ Of course, this is a risky strategy. An integration-policy-fiasco could also undermine the probability of re-election.

\section{REFERENCES}

Alesina, A., \& Edward, L. G. (2004). Fighting poverty in the US and in Europe: A world of difference. New York: Oxford University Press. doi:10.1093/0199267669.001.0001

Alesina, A., \& Eliana La, F. (2005). Preferences for redistribution in the land of opportunities. Journal of Public Economics, 89, 897-931. doi:10.1016/j.jpubeco.2004.05.009

Blekesaune, M., \& Quadagno, J. (2003) Public attitudes toward welfare state policies: A comparative analysis of 24 nations. European Sociological Review, 19, 415-427. doi:10.1093/esr/19.5.415

Bréchon, P., \& Tchernia, J.-F. (Eds.) (2009). La France à travers ses valeurs. Paris: Armand Colin.

Campbell, D. E. (2006). Why we vote: How schools and communities shape our civic life. Princeton, NJ: Princeton University Press.

Crepaz, \& Markus M. L. (2008) Trust beyond Borders. Ann Arbor: University of Michigan Press.

Cusack, T., Iversen, T., \& Rehm, P. (2006). Risk at work: The demand and supply sides of government redistribution. Oxford Review of Economic Policy, 22, 365-389. doi:10.1093/oxrep/grj022

Eger, M. A. (2010). Even in Sweden: The effect of immigration on support for welfare state spending. European Sociological Review, 26, 203-217. doi:10.1093/esr/jcp017

Finseraas, H. (2008). Immigration and preferences for redistribution: An empirical analysis of European survey data. Comparative European Politics, 6, 407-431. doi:10.1057/cep.2008.3

James, E. (1993). Why do different countries choose a different public-private mix of educational services? Journal of Human Resources, 28, 571-592. doi:10.2307/146161

Johnston, R., Bantinga, K., Kymlicka, W., \& Soroka, S. (2010). National identity and support for the welfare state. Canadian Journal of Political Science, 43, 349-377. doi:10.1017/S0008423910000089

Habyarimana, J., Humphreys, M., Posner, D. D., \& Weinstein, J. M. (2007). Why does ethnic diversity undermine public goods provision. American Political Science Review, 101, 709-725. doi: $10.1017 /$ S0003055407070499

Iversen, T., \& Soskice, D. (2001). An asset theory of social policy preferences. American Political Science Review, 95, 875-895.

Keely, L. C., \& Chih, M. T. (2008). Understanding preferences for income redistribution. Journal of Public Economics, 92, 944-961. doi:10.1016/j.jpubeco.2007.11.006 


\section{R. MAGNI BERTON}

Luttmer, E. F. P. (2001). Group loyalty and the taste for redistribution. Journal of Political Economy, 109, 500-528. doi:10.1086/321019

McGhee, E. M., \& Neiman, M. (2010). Concern over immigration and support for public services. California Journal of Politics and Policy, 2.

Moene, K. O., \& Wallerstein, M. (2001). Inequality, social insurance, and redistribution. American Political Science Review, 95, 859-874.

Mueller, J. E. (1973). War, presidents and public opinion. New York: Wiley.

Mueller, D. C., \& Murrell, P. (1986). Interest groups and the size of government. Public Choice, 48, 125-145. doi:10.1007/BF00179727

Roemer, J. E., \& Van der Straeten, K. (2005), Xenophobia and the size of the public sector in France: A politico-economic analysis. Journal of Economics, 86, 95-144. doi:10.1007/s00712-005-0142-x

Roemer, J. E., Lee, W., \& Van der Straeten, K. (2007). Racism, xenophobia and redistribution, a study of multi-issue politics in advanced democracies. Cambridge: Harvard University Press.

Senik, C., Stichnoth, H., \& Van der Straeten, K. (2009). Immigration and natives' attitudes towards the welfare state: Evidence from the European social survey. Social Indicators Research, 91, 345-370. doi:10.1007/s11205-008-9342-4

Soroka, S., Banting, K., \& Johnston, R. (2006). Immigration and redistribution in a global era. In S. Bowles, P. Bardhan, \& M. Wallerstein (Eds.), Globalization and egalitarian redistribution (pp. 261-288). Princeton, NJ: Princeton University Press. 


\section{Appendix I: Cuts for Ordered Estimations with Standard Errors (Corrected, in Table 3, with the Cluster Method, by County)}

Cuts for Table 2.

\begin{tabular}{lll}
\hline & Oprobit 1 & Oprobit 2 \\
\hline Cut 1: from 1 to 2 & $-.17(.14)$ & $-.35(.15)$ \\
Cut 2: from 2 to 3 & $.18(.14)$ & $-.01(.15)$ \\
Cut 3: from 3 to 4 & $.72(.14)$ & $.54(.15)$ \\
Cut 4: from 4 to 5 & $1.07(.14)$ & $.89(.15)$ \\
Cut 5: from 5 to 6 & $1.57(.14)$ & $1.40(.15)$ \\
Cut 6: from 6 to 7 & $1.86(.14)$ & $1.69(.15)$ \\
Cut 7: from 7 to 8 & $2.18(.14)$ & $2.01(.15)$ \\
Cut 8: from 8 to 9 & $2.71(.14)$ & $2.53(.16)$ \\
Cut 9: from 9 to 10 & $2.96(.15)$ & $2.80(.16)$ \\
\hline
\end{tabular}

Cuts for Table 3.

\begin{tabular}{lll}
\hline & Oprobit 1 & Oprobit 2 \\
\hline Cut 1: from 1 to 2 & $-.42(.16)$ & $-.49(.16)$ \\
Cut 2: from 2 to 3 & $-.08(.16)$ & $-.15(.16)$ \\
Cut 3: from 3 to 4 & $.47(.16)$ & $.40(.16)$ \\
Cut 4: from 4 to 5 & $.82(.17)$ & $.75(.17)$ \\
Cut 5: from 5 to 6 & $1.32(.17)$ & $1.26(.17)$ \\
Cut 6: from 6 to 7 & $1.61(.18)$ & $1.55(.18)$ \\
Cut 7: from 7 to 8 & $1.93(.18)$ & $1.88(.18)$ \\
Cut 8: from 8 to 9 & $2.45(.19)$ & $2.39(.19)$ \\
Cut 9: from 9 to 10 & $2.72(.20)$ & $2.66(.19)$ \\
\hline
\end{tabular}

Appendix II: Description of the Control Variables

\begin{tabular}{ccc}
\hline Individual Variables & Mean & Std. Err. \\
\hline Sap Culture & 4.044 & .052 \\
Increase Crime & 4.187 & .049 \\
Tolerance & 2.805 & .025 \\
Oppose Free Market & 5.092 & .045 \\
Income & 6.603 & .063 \\
Gender (female) & .54 & .009 \\
Age & 48.61 & .342 \\
Education & 1.977 & .023 \\
Religiousness & .422 & .009 \\
Migrant Parents & .259 & .011 \\
Contextual Variable & & .009 \\
Unemployment Ratio & 2113 & \\
\hline
\end{tabular}

